\title{
The variance of knowledge and practices about diabetes mellitus in primary health care physicians of Jazan region, Kingdom of Saudi Arabia.
}

\author{
Mohammed A. Alsaleem ${ }^{1 *}$, Mohammed A. Aldarbi ${ }^{2}$, Safar A Alsaleem ${ }^{1}$, Awad Saeed Alsamghan ${ }^{1}$ \\ ${ }^{1}$ Family and Community Medicine Department, King Khalid University, Abha, Kingdom of Saudi Arabia \\ ${ }^{2}$ Consultant Family Medicine, Ministry of Health, Jazan, Kingdom of Saudi Arabia
}

\begin{abstract}
Objective: To assess PHC physicians' knowledge and practice related to DM.

Methods: A total of 109 (PHC) physicians in Jazan Region were interviewed using a questionnaire that comprised personal characteristics data and PHC physicians' assessment of knowledge (15 questions), and practice (10 questions).

Results: Regarding PHC physicians' knowledge, $27.5 \%$ had poor grade, $48.6 \%$ had satisfactory grade while $23.9 \%$ had good grade. Regarding their practice, $\mathbf{5 3 . 2 \%}$ had poor grade, $22 \%$ had satisfactory grade while $24.8 \%$ had good knowledge grade. PHC physicians' knowledge grades differed significantly according to their age groups ( $p=0.041$ ), with highest percentage of "good" knowledge grade among those aged $>40$ y. PHC physicians' practice grades differed significantly according to their age groups $(p=0.009)$, with least percentages of "good" grade among those aged $<30$ y. Practice grades also differed significantly according to nationality $(\mathrm{p}=\mathbf{0 . 0 0 5})$, with none of the Saudi physicians having "satisfactory or good" grades. Practice grades differed significantly according to qualification $(p<0.001)$, with least percentage of "good" grade among those with MBBS degree. Practice grades differed significantly according to duration of experience after graduation $(p<0.001)$, with least percentages of "good" grade among those having least experience.

Conclusions: PHC physicians' knowledge and practice grades in Jazan Region are suboptimal. Better knowledge and practice grades about DM are present among older, non-Saudi, more experienced and higher qualified PHC physicians. Therefore, continuing medical education and training should be enforced for all PHC physicians, especially Saudi, younger, newly graduated PHC physicians.
\end{abstract}

Keywords: Diabetes, Knowledge, Practice, Primary care.

Accepted on April 2, 2018

\section{Introduction}

In both developed and developing nations, Diabetes Mellitus (DM) is one of the largest epidemics the world is currently facing. Despite many therapeutic advances, the incidence of DM continues to rise [1]. Worldwide, the number of diabetics is predicted to double between 2000 and 2030, reaching a pandemic level of 366 million people [2].

Diabetes brings with it a considerable burden. Diabetics have two- to four-fold increased risk of stroke and heart disease compared with the general population, along with an appreciable risk of retinopathy, peripheral nerve damage and renal problems [3]. In the Kingdom of Saudi Arabia (KSA), Bahijri et al. [4] reported that prevalence of diabetes was $18.3 \%$. Prevalence of diabetes was shown to increase with age. For people aged $\geq 50 \mathrm{y}$, it was $46 \%$ for men and $44 \%$ for women.

Diabetes has detrimental effects on a range of health outcomes $[5,6]$ that impair all dimensions of health. It was found to have a notable impact on general health [7] equivalent to that of having cardiovascular conditions, cancer or chronic respiratory disease [8].

In recent decades, care of diabetic patients has shifted from specialist care to Primary Health Care (PHC) [9]. Therefore, proper knowledge and practice of physicians working at PHC facilities are the determining factors in diabetes management [10].

Shera et al. [11] noted that PHC physicians, who are at the first line of defense in treating and guiding diabetics and their family members, are not fully equipped to provide initial and continuing care and counselling, because of the absence of the training at the undergraduate level and continuing medical education and training programs thereafter. Therefore, knowledge and practice studies should be conducted, as a pivotal step toward implementation of targeted educational and training programs and ultimate improvement of care standards for patients with diabetes [12]. 
This study aimed to assess the PHC physicians' knowledge and practice related to diabetes mellitus in Jazan region.

\section{Subjects and Methods}

This cross-sectional study was conducted in Jazan Region during 2016. The study population comprised all PHC physicians in the study area $(\mathrm{N}=270)$. Each participant physician was interviewed by the researchers using a structured questionnaire that included:

- Personal characteristics data: Age, gender, nationality, highest qualification, years of experience after graduation, attendance of continuing education on DM).

- PHC physicians' assessment: Based on thorough review of relevant literature, especially the standards and guidelines of the American Diabetes Association [13], the researcher constructed a questionnaire to assess knowledge and practice of PHC physicians as regard diabetes care. It comprised 25 questions (15 questions on knowledge and 10 questions on practice).

Correctly answered questions or proper practices were assigned a score of (1), while incorrectly answered questions or improper practices were assigned a score of $(0)$. The maximum possible attainable score was (15) for knowledge and (10) for practice. The total achieved scores by the PHC physician was graded as good (>70\%), satisfactory $(60-69 \%)$ or poor $(60 \%)$.

A pilot study was performed by the researcher on 20 PHC physicians. Their responses were not included in the main study. The pilot study aimed to test the study tool as regard clarity and wording. Accordingly, the final form of the data collection tool has been reached.

The list of names of all registered PHC physicians were obtained from Jazan Directorate of Health. Each name was given a serial number. After the exclusion of physicians who participated in the pilot study, a systematic random sample was followed to select $50 \%$ of the PHC physicians. A total of 109 physicians were included, with $87.2 \%$ response rate.

Before conducting the field work, the researchers fulfilled all the necessary official approvals from Jazan Directorate of Health. Before distributing the study questionnaire, PHC physicians were briefly informed about the objectives of this study and were invited to participate in the study, assuring them the full confidentiality and anonymity of any collected data. They were also informed that this study is not a "test" for their evaluation, and no harm is ever expected to occur as a result of their participation in this study.

The Statistical Package for Social Sciences (SPSS version 22.0) was used for data entry and analysis. The descriptive statistics (i.e., frequency, percentage, mean and standard deviation) were calculated. $\chi^{2}$-test, t-test and F-test were applied to test significance of differences in PHC physicians' knowledge and practice grades according to their characteristics. Statistically significant differences were considered at $\mathrm{p}<0.05$.

\section{Results}

Table 1 shows that $13.8 \%$ aged $<30$ y, $56.9 \%$ of physicians aged $30-40 \mathrm{y}$, while $29.4 \%$ aged $>40 \mathrm{y}$. The majority of PHC physicians were males $(82.6 \%)$ and non-Saudi (92.7\%). Most PHC physicians had only a Bachelor degree (74.3\%), while $23.9 \%$ had a Diploma or a Master degree and $1.8 \%$ had a Doctorate or a Fellowship degree. More than half of PHC physicians had less than 10 years' experience after graduation (56\%), while $32.1 \%$ had $10-20$ years of experience and $11.9 \%$ had more than 20 years' experience. Almost one-thirds of PHC physicians $(34.9 \%)$ did not attend courses on diabetes.

Table 2 shows that $27.5 \%$ of PHC physicians had poor knowledge grade, $48.6 \%$ had satisfactory knowledge grade while 23.9\% had good knowledge grade. Regarding PHC physicians' practice grades, $53.2 \%$ of PHC physicians had poor grade, $22 \%$ had satisfactory grade while $24.8 \%$ had good grade.

Table 3 shows that PHC physicians' knowledge grades differed significantly according to their age groups $(p=0.041)$, with highest percentage of "good"

Knowledge grade $(40.6 \%)$ among those aged $>40$ y. However, grades of knowledge of PHC physicians did not differ significantly according to physicians' gender, nationality, qualification, experience after graduation, practice grade, or attending courses on diabetes.

Table 4 shows that PHC physicians' practice grades differed significantly according to their age groups $(p=0.009)$, with least percentages of "good" grade among those aged $<30 \mathrm{y}$. Practice grades also differed significantly according to physicians' nationality $(p=0.005)$, with none of the Saudi physicians having "satisfactory or good" grades. Physicians' practice grades differed significantly according to their highest qualification $(\mathrm{p}<0.001)$, with least percentage of "good" grade among those with MBBS degree (16.9\%). Moreover, practice grades differed significantly according to physicians' duration of experience after graduation $(p<0.001)$, with least percentages of "good" grade among those having least experience. However, PHC physicians' practice grades did not differ significantly according to their gender or attending courses on diabetes.

Table 5 shows that participants knowledge percent scores differed significantly according to their age groups $(p=0.006)$, with highest knowledge mean percent scores among those aged $>40$ y $(75.1 \pm 7.4 \%)$. Moreover, their knowledge percent scores differed significantly according to their duration of experience after graduation $(\mathrm{p}=0.006)$, with highest knowledge mean percent scores among those who had experience $>20 \mathrm{y}$ $(74.9 \pm 8.0 \%)$. However, participants' knowledge mean percent scores did not differ significantly according to their gender, nationality, qualification or attending courses on diabetes.

Table 6 shows that participants practice percent scores differed significantly according to their duration of experience after graduation ( $\mathrm{p}=0.007)$, with highest mean percent scores among those who had experience $10-20$ y $(83.8 \pm 5.1 \%)$. Moreover, 
The variance of knowledge and practices about diabetes mellitus in primary health care physicians of Jazan region, Kingdom of Saudi Arabia

participants practice percent scores differed significantly according to attending courses on diabetes $(\mathrm{p}<0.001)$, with higher mean percent score among those who attended course son diabetes $(80.1 \pm 15.6 \%)$.

However, participants' knowledge mean percent scores did not differ significantly according to their age groups, gender, nationality, or qualification.

Table 1. Characteristics of study sample.

\begin{tabular}{|c|c|c|}
\hline Characteristics & No. & $\%$ \\
\hline \multicolumn{3}{|l|}{ Age groups } \\
\hline$\cdot<30 y$ & 15 & 13.8 \\
\hline$\cdot 30-40 y$ & 62 & 56.9 \\
\hline$\cdot>40 y$ & 32 & 29.4 \\
\hline \multicolumn{3}{|l|}{ Gender } \\
\hline - Male & 90 & 82.6 \\
\hline - Female & 19 & 17.4 \\
\hline \multicolumn{3}{|l|}{ Nationality } \\
\hline - Saudi & 8 & 7.3 \\
\hline - Non-Saudi & 101 & 92.7 \\
\hline \multicolumn{3}{|l|}{ Highest qualifications } \\
\hline$\cdot$ MBBS & 81 & 74.3 \\
\hline · Diploma/Master & 26 & 23.9 \\
\hline - Doctorate/Fellowship & 2 & 1.8 \\
\hline \multicolumn{3}{|c|}{ Experience after graduation } \\
\hline$\cdot<10 y$ & 61 & 56 \\
\hline$\cdot 10-20 y$ & 35 & 32.1 \\
\hline$\cdot>20 y$ & 13 & 11.9 \\
\hline \multicolumn{3}{|c|}{ Attending courses on diabetes } \\
\hline - No & 38 & 34.9 \\
\hline - Yes & 71 & 65.1 \\
\hline
\end{tabular}

Table 2. Overall physicians' knowledge and practice grades.

\begin{tabular}{lll}
\hline Grades & No. & $\%$ \\
\hline Knowledge grades & & \\
\hline Poor & 30 & 27.5 \\
\hline$\cdot$ Satisfactory & 53 & 48.6 \\
\hline$\cdot$ Good & 26 & 23.9 \\
\hline
\end{tabular}

\begin{tabular}{lll}
\hline Practice grades & & \\
\hline$\cdot$ Poor & 58 & 53.2 \\
\hline Satisfactory & 24 & 22 \\
\hline$\cdot$ Good & 27 & 24.8 \\
\hline
\end{tabular}

Table 3. Distribution of physicians' knowledge grades according to their characteristics.

\begin{tabular}{|c|c|c|c|c|c|c|c|}
\hline \multirow[t]{2}{*}{ Characteristics } & \multicolumn{2}{|c|}{ Poor } & \multicolumn{2}{|c|}{ Satisfactory } & \multicolumn{2}{|c|}{ Good } & \multirow[t]{2}{*}{$P$ value } \\
\hline & No. & $\%$ & No. & $\%$ & No. & $\%$ & \\
\hline \multicolumn{8}{|l|}{ Age groups } \\
\hline$\cdot<30 y$ & 3 & 20 & 7 & 46.7 & 5 & 33.3 & \multirow{3}{*}{0.041} \\
\hline$\cdot 30-40 y$ & 20 & 32.3 & 34 & 54.8 & 8 & 12.9 & \\
\hline$\cdot>40 y$ & 7 & 21.9 & 12 & 37.5 & 13 & 40.6 & \\
\hline \multicolumn{8}{|l|}{ Gender } \\
\hline - Male & 27 & 30 & 40 & 44.4 & 23 & 25.6 & \multirow{2}{*}{0.163} \\
\hline Female & 3 & 15.8 & 13 & 68.4 & 3 & 15.8 & \\
\hline \multicolumn{8}{|l|}{ Nationality } \\
\hline - Saudi & 2 & 25 & 4 & 50 & 2 & 25 & \multirow{2}{*}{0.986} \\
\hline - Non-Saudi & 28 & 27.7 & 49 & 48.5 & 24 & 23.8 & \\
\hline \multicolumn{8}{|l|}{ Highest qualifications } \\
\hline$\cdot$ MBBS & 25 & 30.9 & 33 & 40.7 & 23 & 28.4 & \multirow{3}{*}{0.057} \\
\hline · Diploma/Master & 4 & 15.4 & 19 & 73.1 & 3 & 11.5 & \\
\hline - Doctorate/Fellowship & 1 & 50 & 1 & 50 & 0 & 0 & \\
\hline \multicolumn{8}{|l|}{$\begin{array}{l}\text { Experience after } \\
\text { graduation }\end{array}$} \\
\hline$\cdot<10 y$ & 22 & 36.1 & 29 & 47.5 & 10 & 16.4 & \multirow{3}{*}{0.096} \\
\hline$\cdot 10-20 y$ & 5 & 14.3 & 19 & 54.3 & 11 & 31.4 & \\
\hline$\cdot>20 y$ & 3 & 23.1 & 5 & 38.5 & 5 & 38.5 & \\
\hline \multicolumn{8}{|l|}{ Practice grades } \\
\hline - Poor & 18 & 31 & 25 & 43.1 & 15 & 25.9 & \multirow{3}{*}{0.549} \\
\hline - Satisfactory & 7 & 29.2 & 11 & 45.8 & 6 & 25 & \\
\hline - Good & 5 & 18.5 & 17 & 63 & 5 & 18.5 & \\
\hline \multicolumn{7}{|l|}{$\begin{array}{l}\text { Attending courses on } \\
\text { diabetes }\end{array}$} & \multirow{3}{*}{0.059} \\
\hline - No & 15 & 39.5 & 13 & 34.2 & 10 & 26.3 & \\
\hline - Yes & 15 & 21.1 & 40 & 56.3 & 16 & 22.5 & \\
\hline
\end{tabular}

Table 4. Distribution of physicians' practice grades according to their characteristics.

$\begin{array}{llll}\text { Characteristics } & \text { Poor } & \text { Satisfactory } & \text { Good } \\ & & \text { value }\end{array}$




\begin{tabular}{lllll}
\hline No. & $\%$ & No. & $\%$ & No.
\end{tabular}

\begin{tabular}{|c|c|c|c|c|c|c|c|}
\hline \multicolumn{8}{|l|}{ Age groups } \\
\hline$\cdot<30 y$ & 13 & 86.7 & 2 & 13.3 & 0 & 0 & \\
\hline$\cdot 30-40$ y & 28 & 45.2 & 12 & 19.4 & 22 & 35.5 & \\
\hline$\cdot>40 y$ & 17 & 53.1 & 10 & 31.3 & 5 & 15.6 & 0.009 \\
\hline \multicolumn{8}{|l|}{ Gender } \\
\hline Male & 49 & 54.4 & 19 & 21.1 & 22 & 24.4 & \\
\hline · Female & 9 & 47.4 & 5 & 26.3 & 5 & 26.3 & 0.836 \\
\hline \multicolumn{8}{|l|}{ Nationality } \\
\hline Saudi & 8 & 100 & 0 & 0 & 0 & 0 & \\
\hline - Non-Saudi & 50 & 49.5 & 24 & 23.8 & 27 & 26.7 & 0.005 \\
\hline \multicolumn{8}{|l|}{ Highest qualifications } \\
\hline MBBS & 45 & 55.6 & 22 & 26.5 & 14 & 16.9 & \\
\hline Diploma/Master & 13 & 54.2 & 2 & 8.3 & 11 & 45.8 & \\
\hline - Doctorate/Fellowship & 0 & 0 & 0 & 0 & 2 & 100 & $<0.001$ \\
\hline \multicolumn{8}{|c|}{ Experience after graduation } \\
\hline$<10 y$ & 43 & 70.5 & 8 & 13.1 & 10 & 16.4 & \\
\hline$\cdot 10-20 y$ & 12 & 34.3 & 13 & 37.1 & 10 & 28.6 & \\
\hline$>20 y$ & 3 & 23.1 & 3 & 23.1 & 7 & 53.8 & $<0.001$ \\
\hline \multicolumn{8}{|c|}{ Attending courses on diabetes } \\
\hline - No & 24 & 63.2 & 9 & 23.7 & 5 & 13.2 & \\
\hline - Yes & 34 & 47.9 & 15 & 21.1 & 22 & 31 & 0.115 \\
\hline
\end{tabular}

Table 5. Participants' knowledge percent scores (Mean and SD) according to their characteristics.

\begin{tabular}{|c|c|c|c|c|}
\hline Characteristics & No. & Mean & SD & P-value \\
\hline \multicolumn{5}{|l|}{ Age groups } \\
\hline$\cdot<30 y$ & 15 & 68.6 & 10.7 & \multirow{3}{*}{0.006} \\
\hline$\cdot 30-40$ y & 62 & 69.6 & 8.2 & \\
\hline$\cdot>40 y$ & 32 & 75.1 & 7.4 & \\
\hline \multicolumn{5}{|l|}{ Gender } \\
\hline - Male & 90 & 73 & 8.4 & \multirow{2}{*}{0.248} \\
\hline - Female & 19 & 70.7 & 8.2 & \\
\hline \multicolumn{5}{|l|}{ Nationality } \\
\hline - Saudi & 8 & 76.7 & 4.7 & \multirow{2}{*}{0.279} \\
\hline - Non-Saudi & 101 & 72.5 & 8.4 & \\
\hline \multicolumn{5}{|l|}{ Highest qualifications } \\
\hline$\cdot$ MBBS & $' 81$ & 73.2 & 8.7 & \multirow{3}{*}{0.387} \\
\hline - Diploma/Master & 26 & 70.6 & 7.6 & \\
\hline - Doctorate/Fellowship & 2 & 71.3 & 6.3 & \\
\hline
\end{tabular}

\begin{tabular}{|c|c|c|c|c|}
\hline \multicolumn{4}{|c|}{ Experience after graduation } & \multirow{4}{*}{0.006} \\
\hline$\cdot<10 y$ & 61 & 69.1 & 8.8 & \\
\hline$\cdot 10-20 y$ & 35 & 73.3 & 3.8 & \\
\hline$\cdot>20 y$ & 13 & 74.9 & 8 & \\
\hline \multicolumn{4}{|c|}{ Attending courses on diabetes } & \multirow{3}{*}{0.284} \\
\hline - No & 38 & 71.4 & 8.7 & \\
\hline - Yes & 71 & 73.2 & 8.1 & \\
\hline
\end{tabular}

Table 6. Participants' practice percent scores (Mean and SD) according to their characteristics.

\begin{tabular}{lcccc}
\hline Characteristics & No. & Mean & SD & P-value \\
\hline Age groups & & & & \\
\hline$\cdot<30$ y & 15 & 70 & 10 & \\
\hline$\cdot 30-40$ y & 62 & 77 & 16.7 & \\
\hline$\cdot>40$ y & 32 & 75.1 & 17.8 & 0.329 \\
\hline Gender & & & & \\
\hline$\cdot$ Male & 90 & 76.4 & 17.5 & \\
\hline
\end{tabular}


The variance of knowledge and practices about diabetes mellitus in primary health care physicians of Jazan region, Kingdom of Saudi Arabia

\begin{tabular}{|c|c|c|c|c|}
\hline Female & 19 & 72.2 & 14.4 & 0.331 \\
\hline \multicolumn{5}{|l|}{ Nationality } \\
\hline - Saudi & 8 & 75 & 21.2 & \\
\hline - Non-Saudi & 101 & 75.6 & 17 & 0.925 \\
\hline \multicolumn{5}{|l|}{ Highest qualifications } \\
\hline - MBBS & 81 & 74.9 & 17.5 & \\
\hline - Diploma/Master & 26 & 76.4 & 18.7 & \\
\hline - Doctorate/Fellowship & 2 & 79 & 3.2 & 0.892 \\
\hline \multicolumn{5}{|c|}{ Experience after graduation } \\
\hline$\cdot<10 y$ & 61 & 74.5 & 16.1 & \\
\hline$\cdot 10-20 y$ & 35 & 83.8 & 5.1 & \\
\hline$\cdot>20 y$ & 13 & 74.5 & 18.8 & 0.007 \\
\hline \multicolumn{5}{|c|}{ Attending courses on diabetes } \\
\hline - No & 38 & 68 & 16.5 & \\
\hline - Yes & 71 & 80.1 & 15.6 & $<0.001$ \\
\hline
\end{tabular}

\section{Discussion}

Results of the current study revealed that most PHC physicians in Jazan Region were males and non-Saudi.

These personal characteristics are comparable to those described within the study of Khan et al. [9] at PHC centers in Al-Hasa Region, Northern Province of KSA, where females constituted only one fourth of the PHC physicians and $76.8 \%$ of PHC physicians were non-Saudi. Similarly, Alsaleem [14], in Aseer Region, KSA, found that the majority of PHC physicians were males (81.7\%) and non-Saudi (88.9\%).

The less involvement of female physicians in PHC settings may be explained by the conservative community in KSA in general and, especially in the southern regions of the Kingdom. In addition, the high proportion of non-Saudi PHC physicians reflects the need to graduate more physicians and to motivate them to work at the PHC sector.

Results of the present study revealed that more than one fourth of PHC physicians had poor knowledge grade while more than half of them had poor practice grade.

These findings are worse than those reported by Alsaleem [14], who found that $8.5 \%$ of PHC physicians in Aseer Region, KSA, had unsatisfactory knowledge grade while $22.2 \%$ had unsatisfactory practice grade regarding management of DM.

Low knowledge grades regarding DM were also reported among physicians by Trepp et al. [15] in Switzerland, who found an overall $43 \%$ of correctly answered questions by medical staff on the knowledge of inpatient diabetes care. In Iran, Peimani et al. [16] reported that among $71 \%$ of physicians had enough knowledge about diabetes, while most of physicians had poor practice abilities. Onyiriuka et al. [17] reported that Nigerian physicians had knowledge gaps and suboptimal practices regarding DM. They suggested that most

physicians require additional education, focusing on diabetes mellitus to provide an acceptable level of care to diabetic patients, especially children and adolescents.

Knowledge and practice grades of participant PHC physicians in the present study were significantly better among older, more experienced after graduation and highly qualified PHC physicians.

This finding is in accordance with that of Alsaleem [14], who reported significantly positive correlation between PHC physicians' age and years of experience with their knowledge and practice scores.

These findings demonstrate that PHC physicians' knowledge and practice regarding management of DM increases with their real-life work.

This study showed that knowledge and practice grades of PHC physicians did not differ according to their gender.

These findings are in agreement with those of Alsaleem [14], but in disagreement with those of Khan et al. [10], in Al-Hasa District, KSA, who reported that knowledge and practice scores for female general practitioners were significantly lower than those of the male general practitioners.

The lack of significant differences in PHC physicians' knowledge and practice grades according to gender in the present study indicates that the need to improve PHC physicians' knowledge and practice should cover all PHC physicians.

The present study showed that grades of practice of PHC physicians were significantly better among non-Saudi PHC physicians than Saudi PHC physicians.

Similarly, Alsaleem [14] in Aseer Region and Khan et al. [10], in Al-Hasa District, revealed that the knowledge and practice scores for Saudi physicians were significantly lower compared with non-Saudi physicians.

The reason why non-Saudi PHC physicians showed better knowledge and practice than Saudi physicians may be explained by the fact that the Saudi Ministry of Health usually employs the best foreign applying physicians and end the contract of those who prove incompetent. Moreover, this finding indicates the necessity to emphasize teaching and training of undergraduate medical students on management of DM at Saudi medical schools.

This study revealed that more than one third of PHC physicians did not attend any educational course or program on diabetes. Nevertheless, knowledge and practice grades of PHC physicians who attended educational courses on diabetes did not differ significantly according to attending courses on diabetes.

Alsaleem [14] reported that $62.1 \%$ of PHC physicians did not attend any educational course or educational program on diabetes and those who attended educational courses or training workshops on DM had significantly better knowledge and practice grades than those who did not. 
Junod [18] stated that investments for improvements in medical education suffer from obstacles of this kind. A systemically organized inpatient diabetes service headed by a diabetologist providing regular training and support for residents has been recommended by professional societies and experts, but is frequently lacking [19]. Trepp et al. [15] noted that in hospitals without a diabetologist, training and support depends on the qualifications of the remaining attending physicians. Considering the inadequate performance of attending physicians not specifically trained in diabetes management, hospitals without a diabetologist may need to focus primarily on re-education of their attending staff.

Akl et al. [20] and Jabbar et al. [21] reported that courses of continuing education are essential to correct physicians' knowledge and practice. All educational programs that update physicians' knowledge are more effective than the traditional methods that only emphasize on physicians to follow the standards of care.

The lack of significant differences in PHC physicians' knowledge and practice in the present study according to attending courses on DM indicates the necessity to revise the provided educational materials and the need to assess the effectiveness of such courses.

In conclusion, PHC physicians' knowledge and practice grades in Jazan Region are suboptimal. Better knowledge and practice grades about DM are present among older, non-Saudi, more experienced and higher qualified PHC physicians. Therefore, continuing medical education and training should be enforced for all PHC physicians, especially Saudi, younger, newly graduated PHC physicians.

\section{References}

1. Harjutsalo V, Sjöberg L, Tuomilehto J. Time trends in the incidence of type 1 diabetes in Finnish children: a cohort study. Lancet 2008; 371: 1777-1782.

2. Hossain P, Kawar B, El Nahas M. Obesity and diabetes in the developing world--a growing challenge. N Engl J Med 2007; 356: 213-215.

3. Eljedia A, Mikolajczyk RT, Kraemer A, Laaser U. Healthrelated quality of life in diabetic patients and controls without diabetes in refugee camps in the Gaza strip: a cross-sectional study. BMC Public Health 2006, 6: 268.

4. Bahijri SM, Jambi HA, Al Raddadi RM, Ferns G, Tuomilehto J. The prevalence of diabetes and prediabetes in the adult population of Jeddah, Saudi Arabia-a community-based survey. PLOS one 2016.

5. Reddy SS. Health outcomes in type 2 diabetes. Int J Clin Pract Suppl 2000; 46-53.

6. Stewart AL, Greenfield S, Hays RD, Wells K, Rogers WH, Berry SD, McGlynn EA, Ware JE. Functional status and well-being of patients with chronic conditions. Results from the Medical Outcomes Study. JAMA 1989; 262: 907-913.

7. Alonso J, Ferrer M, Gandek B, Ware JE Jr, Aaronson NK, Mosconi P, Rasmussen NK, Bullinger M, Fukuhara S,
Kaasa S, Leplege A, IQOLA Project Group. Health-related quality of life associated with chronic conditions in eight countries: results from the International Quality of Life Assessment (IQOLA) Project. Qual Life Res 2004; 13: 283-298.

8. Sprangers MA, de Regt EB, Andries F, van Agt HM, Bijl RV, de Boer JB, Foets M, Hoeymans N, Jacobs AE, Kempen GI, Miedema HS, Tijhuis MA, de Haes HC. Which chronic conditions are associated with better or poorer quality of life? J Clin Epidemiol 2000; 53: 895-907.

9. Khan AR, Al Abdul Lateef ZN, Khamseen MB. Knowledge, attitude and practice of Ministry of Health primary health care physicians in the management of type 2 diabetes mellitus: A cross-sectional study in the Al-Hasa District of Saudi Arabia, 2010. Niger J Clin Pract 2011; 14: 52-59.

10. Khunti K, Ganguli S. Who looks after people with diabetes: primary or secondary care? J R Soc Med 2000; 93: 183-186.

11. Shera AS, Jawad F, Basit A. Diabetes related knowledge, attitude and practices of family physicians in Pakistan. J Pak Med Assoc 2002; 52: 465-470.

12. Clement S. Better glycemic control in the hospital: beneficial and feasible. Cleve Clin J Med 2007; 74: 111-112, 114-120.

13. American Diabetes Association. Standards of medical care in diabetes-2013. Diabetes Care 2013; 36: 11-66.

14. Alsaleem MA. Assessment of primary health care physicians knowledge and practices about diabetes mellitus in Aseer region, Kingdom of Saudi Arabia. KKU J Med Sci 2016; 2: 1-8.

15. Trepp R, Wille T, Wieland T, Reinhart WH. Diabetesrelated knowledge among medical and nursing house staff. Swiss Med Wkly 2010; 140: 370-375.

16. Peimani M, Tabatabaei-Malazy O, Heshmat R. Knowledge, Attitude and Practice of physicians in the field of diabetes and its complications; A pilot study. Iran J Diab Lipid Disord 2010; 9: 1-7.

17. Onyiriuka AN, Oluwayemi IO, Achonwa CJ, Abdullahi M, Oduwole AO, Oyenusi EE, Fakeye-Udeogu OB. Nigerian physicians knowledge, attitude and practices regarding diabetes mellitus in the paediatric age group. J Commun Med Prim Health Care 2016; 28: 52-58.

18. Junod AF. Will there be room for the teaching of internal medicine in a university hospital? Swiss Med Wkly 2002; 132: 4-6.

19. Lubitz CC, Seley JJ, Rivera C, Sinha N, Brillon DJ. The perils of inpatient hyperglycemia management: how we turned apathy into action. Diabetes Spectr 2007; 20: 18-21.

20. Akl OA, Khairy AE, Abdel-Aal NM, Deghedi BS, Amer ZF. Knowledge, attitude, practice and performance of family physicians concerning holistic management of hypertension. J Egypt Public Health Assoc 2006; 81: 337-353. 
The variance of knowledge and practices about diabetes mellitus in primary health care physicians of Jazan region, Kingdom of Saudi Arabia

21. Jabbar A, Hameed A, Chawla R, Akhter J. How well do Pakistani patients and physicians adhere to standards of diabetes care? Int J Diab Dev Ctries 2007; 27: 93-96.

\section{*Correspondence to}

Mohammed A. Alsaleem

Family and Community Medicine Department

King Khalid University

Kingdom of Saudi Arabia 